\title{
Enhanced malic acid production from glycerol with high-cell density Ustilago trichophora TZ1 cultivations
}

\author{
Thiemo Zambanini ${ }^{1}$, Wiebke Kleineberg ${ }^{1}$, Eda Sarikaya ${ }^{1}$, Joerg M. Buescher ${ }^{2}$, Guido Meurer ${ }^{2}$, Nick Wierckx ${ }^{{ }^{*}}$ \\ and Lars M. Blank'
}

\begin{abstract}
Background: In order to establish a cost-efficient biodiesel biorefinery, valorization of its main by-product, crude glycerol, is imperative. Recently, Ustilago trichophora TZ1 was found to efficiently produce malic acid from glycerol. By adaptive laboratory evolution and medium optimization, titer and rate could be improved significantly.

Results: Here we report on the investigation of this strain in fed-batch bioreactors. With pH controlled at 6.5 (automatic $\mathrm{NaOH}$ addition), a titer of $142 \pm 1 \mathrm{~g} \mathrm{~L}^{-1}$ produced at an overall rate of $0.54 \pm 0.00 \mathrm{~g} \mathrm{~L}^{-1} \mathrm{~h}^{-1}$ was reached by optimizing the initial concentrations of ammonium and glycerol. Combining the potential of bioreactors and $\mathrm{CaCO}_{3}$ as buffer system, we were able to increase the overall production rate to $0.74 \pm 0.06 \mathrm{~g} \mathrm{~L}^{-1} \mathrm{~h}^{-1}$ with a maximum production rate of $1.94 \pm 0.32 \mathrm{~g} \mathrm{~L}^{-1}$ reaching a titer of $195 \pm 15 \mathrm{~g} \mathrm{~L}^{-1}$. The initial purification strategy resulted in $90 \%$ pure calcium malate as solid component. Notably, the fermentation is not influenced by an increased temperature of up to $37^{\circ} \mathrm{C}$, which reduces the energy required for cooling. However, direct acid production is not favored as at a lowered $\mathrm{pH}$ value of $\mathrm{pH} 4.5$ the malic acid titer decreased to only $9 \pm 1 \mathrm{~g} \mathrm{~L}^{-1}$. When using crude glycerol as substrate, only the product to substrate yield is decreased. The results are discussed in the context of valorizing glycerol with Ustilaginaceae.
\end{abstract}

Conclusions: Combining these results reveals the potential of U. trichophora TZ1 to become an industrially applicable production host for malic acid from biodiesel-derived glycerol, thus making the overall biodiesel production process economically and ecologically more feasible.

Keywords: Bioreactor, Fed-batch, Crude glycerol, Malic acid, Ustilago trichophora

\section{Background}

The production of biodiesel, as one possible supplement for petroleum-derived fuels, is a great opportunity to drive the needed switch to a bio-based economy. This is also reflected in the ever increasing amount of produced biodiesel, which is predicted to be 123 million tons per year for 2016 [1]. However, this process results in a $10 \%$ $(w / v)$ waste stream of crude glycerol, decreasing the profit margin and the ecological feasibility. Valorization

\footnotetext{
*Correspondence: nick.wierckx@rwth-aachen.de

${ }^{1}$ Institute of Applied Microbiology - iAMB, Aachen Biology

and Biotechnology - ABBt, RWTH Aachen University, Worringerweg 1,

Aachen 52074, Germany

Full list of author information is available at the end of the article
}

of this large low-value side stream by microbial conversion is considered as a promising strategy to add value to the overall biodiesel biorefinery concept. Microbial production processes starting from glycerol as substrate have been investigated and reviewed intensively over the last years resulting in production processes for many different products [2-4].

The $\mathrm{C}_{4}$-dicarboxylic acid malic acid is widely used as acidulant and flavor enhancer in the food industry and has also received great interest in non-food applications, such as metal cleaning, textile finishing, and pharmaceuticals production [5]. Even though the annual world production in 2006 was only about 40,000 tons, future use of malic acid is predicted to be above 200,000 tons 
per year as raw material of a novel biodegradable polymer-polymalic acid [5, 6]. In 2004, malic acid has been identified by the Department of Energy (DOE) as one of the top twelve building block chemicals to be produced from renewable biomass at bulk scale [7]. Traditionally, malic acid was obtained by the extraction from apple juice at low yields [8]. Today malic acid can be produced both chemically and biotechnologically. In current industrial production processes, it is mainly manufactured by chemical synthesis via hydration of maleic or fumaric acid producing a racemic mixture of $\mathrm{D}$ - and L-isomers [9]. Alternatively, enzymatic hydration of fumarate by immobilized bacterial cells of Brevibacterium ammoniagenes or Bacillus flavum containing a highly active fumarase yields enantiomerically pure L-malic acid [10]. However, these production methods are costly and substrates for the synthesis of malic acid are derived from non-sustainable petrochemical feedstocks [5]. Thus, as TCA cycle intermediate, bio-based microbiological production processes based on renewable substrates for malic acid have become the focus of research. The first patented microorganism producing malic acid was Aspergillus flavus [11]. The fermentation process was improved by medium optimization resulting in a final titer of 113 from $120 \mathrm{~g} \mathrm{~L}^{-1}$ glucose as substrate [8]. However, this organism is not applicable for industrial malic acid production, especially for food applications, due to the production of aflatoxins [12]. Besides Escherichia coli [13, 14] and Saccharomyces cerevisiae [15], an Aspergillus oryzae strain has been investigated as production organism. This strain, overexpressing a $\mathrm{C}_{4}$-dicarboxylate transporter, pyruvate carboxylase, and malate dehydrogenase produced a final titer of $154 \mathrm{~g} \mathrm{~L}^{-1}$ malic acid from glucose at a rate of $0.94 \mathrm{~g} \mathrm{~L}^{-1} \mathrm{~h}^{-1}[16]$.

Recently we reported that Ustilago trichophora TZ1, a member of the family of Ustilaginaceae which is known to produce organic acids naturally [17], is able to produce malic acid from glycerol [18]. This strain has been adapted to glycerol by laboratory evolution, increasing glycerol uptake rates. After medium optimization, the final malic acid titer reached $196 \mathrm{~g} \mathrm{~L}^{-1}$ produced from $250 \mathrm{~g} \mathrm{~L}^{-1}$ glycerol at an average rate of $0.4 \mathrm{~g} \mathrm{~L}^{-1} \mathrm{~h}^{-1}$ in shake flasks. The limiting factor in these shake flask cultivations was either glycerol depletion or problems concerning oxygen transfer, which result from viscous culture broth.

Here we report on malic acid production with $U$. trichophora TZ1 in bioreactors to overcome abovementioned problems. Further, the production process was investigated at differing temperature profiles and $\mathrm{pH}$ values to determine the boundary conditions of an eventual industrial process, and the effects of using high concentrations of crude glycerol as a substrate were evaluated.

\section{Results and discussion}

Bioreactors enable higher cell density resulting in higher volumetric production rates

The potential of Ustilaginaceae as production organisms of different industrially relevant compounds, such as organic acids, lipids, or polyols, has been discussed and demonstrated consistently over the last years [17, 19-25]. Recently, $U$. trichophora was found to produce malic acid naturally from glycerol at high titers. By adaptive laboratory evolution and medium optimization, the production rate of this strain in shake flask could be improved to around $0.4 \mathrm{~g} \mathrm{~L}^{-1} \mathrm{~h}^{-1}$ reaching titers near $200 \mathrm{~g} \mathrm{~L}^{-1}$ [18]. All cultivations ended either upon glycerol depletion or by oxygen limitations due to the viscosity of the cultures. These viscosity issues resulted mainly from the buffering agent, $\mathrm{CaCO}_{3}$, reacting with produced malate, forming insoluble calcium malate. Although this precipitation might be beneficial for alleviation of product inhibition, it greatly hinders oxygenation of the culture broth in shaking flasks [26].

To overcome handling issues with insoluble components and to avoid glycerol depletion, here we investigate the production process with $U$. trichophora TZ1 in bioreactors, in which the $\mathrm{pH}$ was kept constant by titration with $\mathrm{NaOH}$. By this, effects of insoluble buffer components on production can be minimized. Further, by feeding additional glycerol prior to depletion, malate titers might be further increased. Additionally, better oxygenation through sparging and stirring, which has a strong influence on microbial organic acid production processes [27], also enables higher cell densities.

Initially, $U$. trichophora TZ1 was cultured in $\mathrm{pH}$ controlled bioreactors ( $\mathrm{pH}$ 6.5, $\mathrm{NaOH}$ titration) in MTM containing $0.8 \mathrm{~g} \mathrm{~L}^{-1} \mathrm{NH}_{4} \mathrm{Cl}$ and $200 \mathrm{~g} \mathrm{~L}^{-1}$ initial glycerol. An additional $160 \mathrm{~g}$ glycerol was fed when the concentration dropped below $50 \mathrm{~g} \mathrm{~L}^{-1}$. This results in a slight drop in the measured malate concentrations due to the dilution of the culture broth. The resulting titer $\left(119.9 \pm 0.9 \mathrm{~g} \mathrm{~L}^{-1}\right)$ and rate $\left(0.13 \pm 0.00 \mathrm{~g} \mathrm{~L}^{-1} \mathrm{~h}^{-1}\right)$ (Fig. 1b) were significantly lower than those reached in shake flasks with $\mathrm{CaCO}_{3}[18]$. Likely, these reductions can be attributed to product inhibition caused by the drastically increased dissolved malate concentration in $\mathrm{NaOH}$-titrated cultures. To improve the production rate, the cell density was increased by using higher concentrations of the growth-limiting nutrient $\mathrm{NH}_{4} \mathrm{Cl}\left(1.6,3.2\right.$, and $\left.6.4 \mathrm{~g} \mathrm{~L}^{-1}\right)$. Dependent on the initial $\mathrm{NH}_{4} \mathrm{Cl}$ concentration, a delay in the onset of malate production could be observed, which can be attributed to a longer growth phase. Maximal $\mathrm{OD}_{600}$, however, could be increased from $42 \pm 2$ with $0.8 \mathrm{~g} \mathrm{~L}^{-1} \mathrm{NH}_{4} \mathrm{Cl}$ to $80 \pm 0$ and $115 \pm 1$ using 1.6 and $3.2 \mathrm{~g} \mathrm{~L}^{-1} \mathrm{NH}_{4} \mathrm{Cl}$, respectively (Fig. 1a). As expected, also the overall volumetric malic acid production rate (from the beginning 

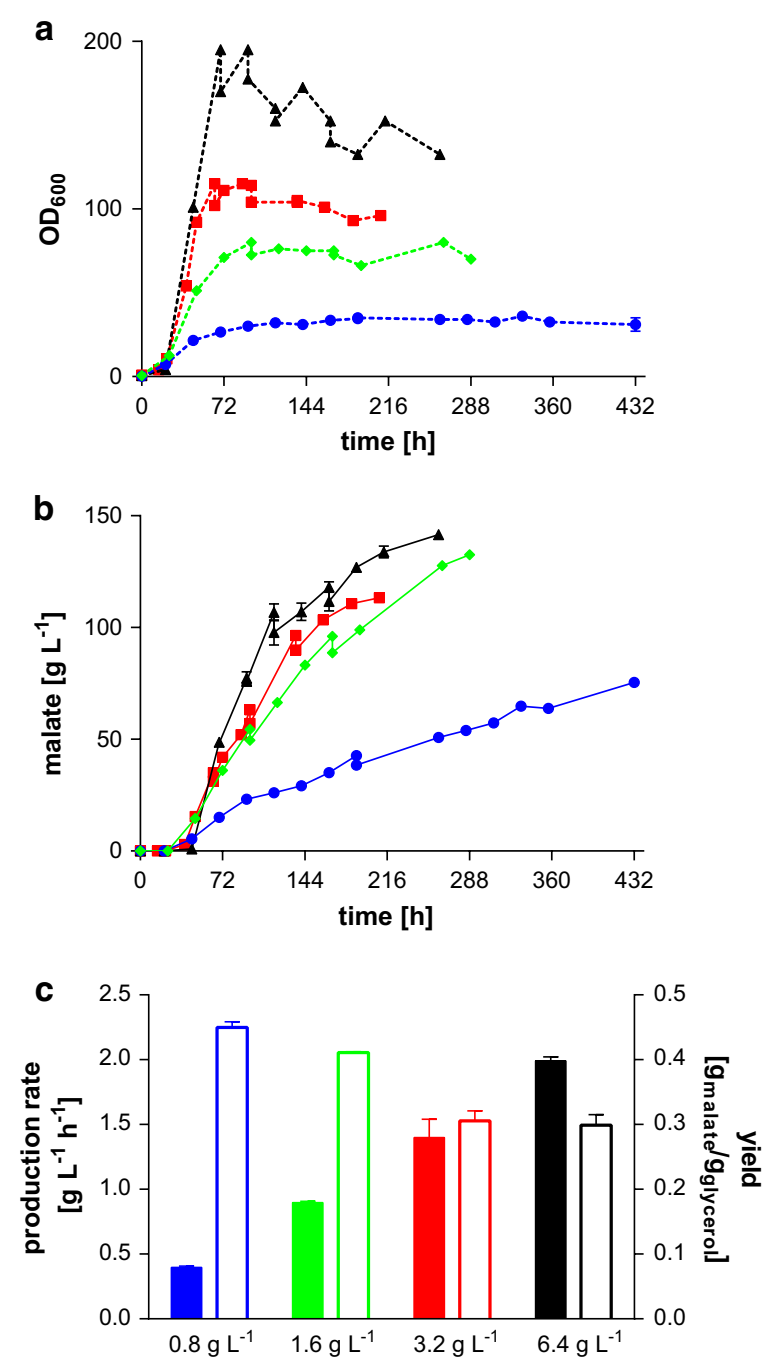

Fig. 1 Fermentation of Ustilago trichophora TZ1 with different $\mathrm{NH}_{4} \mathrm{Cl}$ concentrations. a $\mathrm{OD}_{600}$, b malate production, c maximum malate production rate (solid bars) and yield (open bars) for controlled batch fermentations in MTM containing $200 \mathrm{~g} \mathrm{~L}^{-1}$ initial glycerol at $30^{\circ} \mathrm{C}$ and pH 6.5 with DO kept at $80 \%$. Colors indicate different initial $\mathrm{NH}_{4} \mathrm{Cl}$ concentrations: $0.8 \mathrm{~g} \mathrm{~L}^{-1}$ (circles, blue), $1.6 \mathrm{~g} \mathrm{~L}^{-1}$ (diamonds, green), $3.2 \mathrm{~g} \mathrm{~L}^{-1}$ (squares, red), and $6.4 \mathrm{~g} \mathrm{~L}^{-1}$ with doubled concentrations of all medium components except glycerol (triangles, black). Values for $0.8 \mathrm{~g} \mathrm{~L}^{-1}$ are only shown until $432 \mathrm{~h}$; however, a further increase in concentration to a final titer of $120 \pm 1 \mathrm{~g} \mathrm{~L}^{-1}$ could be observed until $908 \mathrm{~h}$ of cultivation. Error bars indicate deviation from the mean $(n=2)$

of cultivation until the end) increased to $0.46 \pm 0.02$ and $0.54 \pm 0.07 \mathrm{~g} \mathrm{~L}^{-1} \mathrm{~h}^{-1}$ with 1.6 and $3.2 \mathrm{~g} \mathrm{~L}^{-1} \mathrm{NH}_{4} \mathrm{Cl}$, respectively (Fig. 1b). $6.4 \mathrm{~g} \mathrm{~L}^{-1} \mathrm{NH}_{4} \mathrm{Cl}$, however, did not lead to increased biomass and subsequently production, but had the opposite effect (data not shown). In these cultures, $\mathrm{NH}_{4} \mathrm{Cl}$ was no longer depleted during the fermentation. A similar effect was observed for itaconate producing Ustilago maydis $\mathrm{MB} 215$ in $\mathrm{MTM}$ with $\mathrm{NH}_{4} \mathrm{Cl}$ concentrations above $4 \mathrm{~g} \mathrm{~L}^{-1}$ [19]. This likely explains the reduced productivity, since nitrogen limitation is the most efficient trigger for organic acid production with Ustilaginaceae [28]. To compensate for this effect, all medium components except for glycerol were doubled in combination with $6.4 \mathrm{~g} \mathrm{~L}^{-1} \mathrm{NH}_{4} \mathrm{Cl}$ in a subsequent fermentation, resulting in an overall volumetric production rate of $0.54 \pm 0.00 \mathrm{~g} \mathrm{~L}^{-1} \mathrm{~h}^{-1}$, with a maximal production rate of $1.99 \pm 0.04 \mathrm{~g} \mathrm{~L}^{-1} \mathrm{~h}^{-1}$ between 45 and $69 \mathrm{~h}$ (Fig. 1b).

As expected, an increase in the growth-limiting nutrient led to more biomass formation and consequently to a higher volumetric production rate. There is a good correlation between the maximum malate production rate and the initial $\mathrm{NH}_{4} \mathrm{Cl}$ concentration, indicating that the production rate could be further increased as long as secondary limitations are excluded. However, further increases will strongly impact the product yield, since more glycerol is used for biomass formation. Assuming no $\mathrm{CO}_{2}$ co-consumption, the maximum theoretical yield would be $0.75 \mathrm{~mol}$ malate per mole glycerol. However, the glycerol needed for biomass production reduces this maximum, and this reduction is proportional to the initial ammonium concentration. Based on the glycerol consumption during the growth phase (Fig. 1a), approximately $11.5 \mathrm{~g}$ of glycerol are needed for biomass formation per gram $\mathrm{NH}_{4} \mathrm{Cl}$. Thus, taking into account the total amount of glycerol consumed by each culture, biomass formation reduces the maximum theoretical yield to $0.73,0.71,0.68$, and $0.62 \mathrm{~mol} \mathrm{~mol}^{-1}$, for $0.8,1.6,3.2$, and $6.4 \mathrm{~g} \mathrm{~L}^{-1} \mathrm{NH}_{4} \mathrm{Cl}$, respectively. This in part explains the reduction in the observed yields in the cultures with higher $\mathrm{NH}_{4} \mathrm{Cl}$ concentrations, although in general the yields are only $30-55 \%$ of these theoretical maxima, suggesting that the impact of biomass formation is at the moment relatively low. Improvement in the product yield should be the main focus of future optimization, possibly by the reduction in by-product formation through the disruption of competing pathways. The improvement in specificity for the production of one organic acid is generally considered a promising approach to improve microbial organic acid production. For $U$. trichophora TZ1, however, besides 5-10 $\mathrm{g} \mathrm{L}^{-1}$ succinate, no significant amounts of other organic acids were found in HPLC analysis. Additionally, $\mathrm{CO}_{2}$ and extra- and intracellular lipids are most likely the main by-products. The formation of lipids under organic acid production conditions and their effect on the cells have been described extensively $[28,29]$. These by-products can be reduced by knock-out of single genes in the responsive gene clusters [30-32].

Since a significant influence of the starting glycerol concentration on the malic acid production rate has been observed in shake flasks [18], this relation was also 
studied in bioreactors. Concentration steps of $50 \mathrm{~g} \mathrm{~L}^{-1}$ between 150 and $300 \mathrm{~g} \mathrm{~L}^{-1}$ were investigated in MTM containing $3.2 \mathrm{~g} \mathrm{~L}^{-1} \mathrm{NH}_{4} \mathrm{Cl}$. Additional $160 \mathrm{~g}$ glycerol was fed to the cultures one time (300 $\mathrm{g} \mathrm{L}^{-1}$ initial glycerol), two times (150 and $200 \mathrm{~g} \mathrm{~L}^{-1}$ initial glycerol), and four times $\left(250 \mathrm{~g} \mathrm{~L}^{-1}\right.$ initial glycerol), when the concentration became lower than $50-100 \mathrm{~g} \mathrm{~L}^{-1}$ (150 and $200 \mathrm{~g} \mathrm{~L}^{-1}$ initial glycerol) or $200 \mathrm{~g} \mathrm{~L}^{-1}$ (250 and $300 \mathrm{~g} \mathrm{~L}^{-1}$ initial glycerol). Thus, after the consumption of the initial glycerol, its concentrations generally ranged between 50 and $150 \mathrm{~g} \mathrm{~L}^{-1}$ (150 and $200 \mathrm{~g} \mathrm{~L}^{-1}$ initial glycerol) and 100 and $250 \mathrm{~g} \mathrm{~L}^{-1}$ (250 and $300 \mathrm{~g} \mathrm{~L}^{-1}$ initial glycerol). Just as in shake flasks, increasing initial glycerol concentrations between 150 and $300 \mathrm{~g} \mathrm{~L}^{-1}$ decreased growth rates, final $\mathrm{OD}_{600}$ and malic acid production rates (Fig. 2). Possibly, higher glycerol concentrations impose a stress upon the cells. This is also known in other organisms, such as $S$. cerevisiae, even though lower glycerol concentrations are generally known to contribute to osmotolerance in different yeast, such as Zygosaccharomyces rouxii and S. cerevisiae $[33,34]$.

\section{Ustilago trichophora TZ1 accepts a broad temperature range for production}

In 1990, Guevarra and Tabuchi investigated the influence of temperature on itaconic acid production and growth of Ustilago cynodontis [35]. They could show that the highest tested temperature $\left(35^{\circ} \mathrm{C}\right)$ was best for cell growth. However, the lowest tested temperature $\left(25^{\circ} \mathrm{C}\right)$ resulted in the highest organic acid titers. To investigate influences of temperature on acid production by $U$. trichophora TZ1, cells were grown at $30{ }^{\circ} \mathrm{C}$ and the temperature was changed after the growth phase to 25 and $35{ }^{\circ} \mathrm{C}$. In a third approach, heating was disabled and cooling was only activated at temperatures exceeding $37^{\circ} \mathrm{C}$ (Fig. 3). In this case, the temperature remained at this maximum after $30 \mathrm{~h}$, indicating the considerable heat generated by these high-density cultures. As shown in Fig. 3b, malic acid production was not influenced by temperatures exceeding $30^{\circ} \mathrm{C}$. However, $25^{\circ} \mathrm{C}$ resulted in a lower malic acid production rate yet reaching the same final titer of approximately $120 \mathrm{~g} \mathrm{~L}^{-1}$.

Since malic acid production with $U$. trichophora TZ1 was not influenced by elevated temperatures and reduced use of heating and cooling systems could reduce operating costs, preliminary experiments without a heating and cooling system were conducted. These experiments indicated that uncontrolled temperatures above $37{ }^{\circ} \mathrm{C}$ negatively influence the malic acid production process. This was also observed in 2008 by Kuenz for itaconic acid production with Aspergillus terreus [36]. A temperature increase from 27 to $30{ }^{\circ} \mathrm{C}$ resulted in a $60 \%$ increased production rate. Further increasing the temperature to 33 and $37{ }^{\circ} \mathrm{C}$ resulted in a $20-40 \%$ increase compared to $30{ }^{\circ} \mathrm{C}$. However, a process temperature of $40{ }^{\circ} \mathrm{C}$ reduced itaconic acid production drastically [36].

\section{Decreasing $\mathrm{pH}$ values drastically lower malic acid production}

In a next step, the fermentation was investigated in respect to growth medium $\mathrm{pH}$. Malic acid production with $U$. trichophora TZ1 was investigated in bioreactors at $\mathrm{pH} 4.5,5.5$, and 6.5. The tested $\mathrm{pH}$ range neither influenced growth rate (Fig. 4a), nor morphology (data not shown). However, maximal $\mathrm{OD}_{600}$ was higher at lower $\mathrm{pH}$. Malic acid production was clearly lowered by decreasing $\mathrm{pH}$ reaching $113 \pm 15 \mathrm{~g} \mathrm{~L}^{-1}(\mathrm{pH}$ 6.5), $64 \pm 6 \mathrm{~g} \mathrm{~L}^{-1}$ (pH 5.5), and $9 \pm 1 \mathrm{~g} \mathrm{~L}^{-1}$ (pH 4.5). In fungi such as Aspergillus, Saccharomyces, and Yarrowia, organic acids such as succinate, itaconate, and malate are produced best at low $\mathrm{pH}$, with some exceptions [27, 3741]. For Ustilaginaceae, mainly near neutral $\mathrm{pH}$ values are
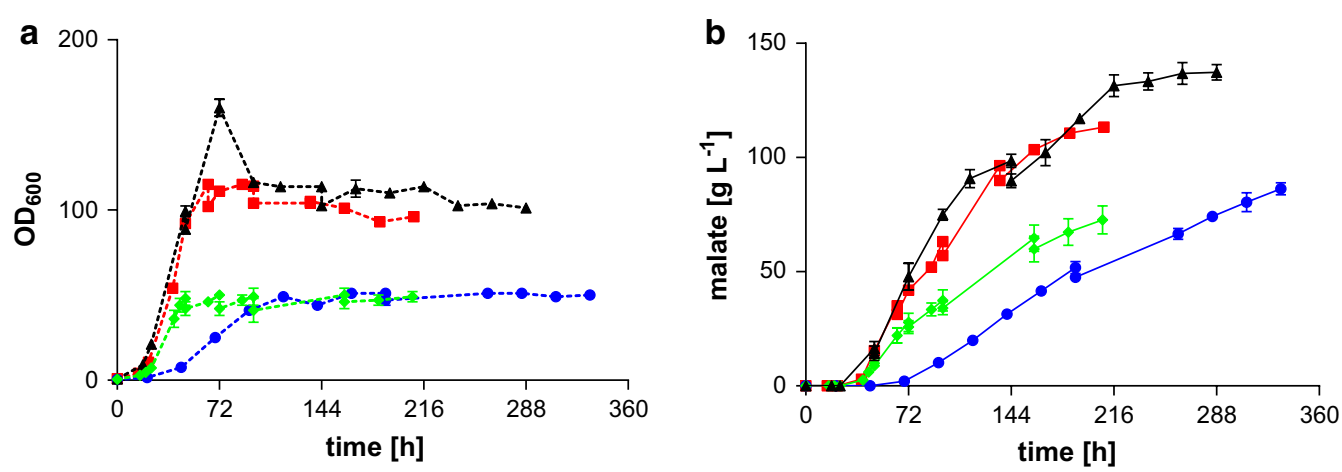

Fig. 2 Fermentation of Ustilago trichophora TZ1 with different initial glycerol concentrations. a $\mathrm{OD}_{600}$, $\mathbf{b}$ malate production for fermentations in MTM containing $3.2 \mathrm{~g} \mathrm{~L}^{-1} \mathrm{NH}_{4} \mathrm{Cl}$ at $30^{\circ} \mathrm{C}$ and pH 6.5 with DO kept at $80 \%$. Colors indicate different initial glycerol concentrations: $300 \mathrm{~g} \mathrm{~L}^{-1}$ (circles, blue), $250 \mathrm{~g} \mathrm{~L}^{-1}$ (diamonds, green), $200 \mathrm{~g} \mathrm{~L}^{-1}$ (squares, red), $150 \mathrm{~g} \mathrm{~L}^{-1}$ (triangles, black). Additional $160 \mathrm{~g}$ glycerol was added when the concentration dropped below $50 \mathrm{~g} \mathrm{~L}^{-1}$. Error bars indicate deviation from the mean $(n=2)$ 

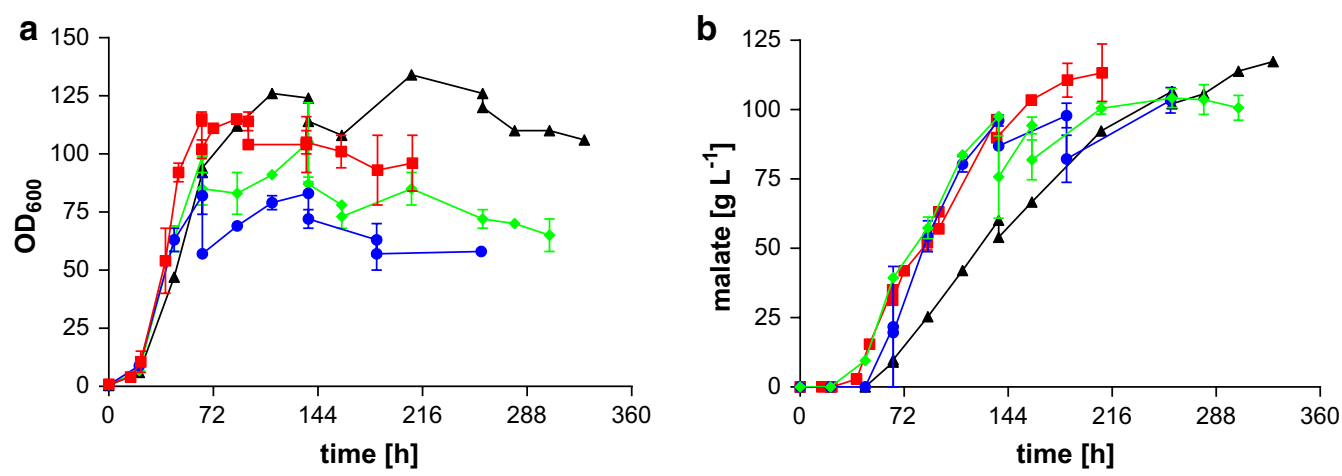

Fig. 3 Fermentation of Ustilago trichophora TZ1 at different temperatures. a $\mathrm{OD}_{600}$, b malate concentration for fermentations in MTM containing $200 \mathrm{~g} \mathrm{~L}^{-1}$ initial glycerol and $3.2 \mathrm{~g} \mathrm{~L}^{-1} \mathrm{NH}_{4} \mathrm{Cl}$ at $30^{\circ} \mathrm{C}$ and pH 6.5 with DO kept at $80 \%$. Colors indicate different temperatures: $25^{\circ} \mathrm{C}$ (triangles, black), $30^{\circ} \mathrm{C}$ (squares, red), $35^{\circ} \mathrm{C}$ (circles, blue), and $37^{\circ} \mathrm{C}$ (diamonds, green). Error bars indicate deviation from the mean $(n=2)$

best for organic acid production [19], although exceptions such as $U$. cynodontis have been reported [17].

Production both at high and at low $\mathrm{pH}$ value has different opportunities and disadvantages on microbial organic acid production and downstream processing. A low $\mathrm{pH}$ can help to lower the risk of contamination in industrialscale fermentations. Further, the production of environmentally unfriendly by-products can be reduced, since during the production process less titration agents, such as $\mathrm{CaCO}_{3}$ or $\mathrm{Ca}(\mathrm{OH})_{2}$, are needed, which in the later process have to be disposed of. However, the same by-product, namely gypsum, is also produced in the downstream process of microbial citric acid production, resulting from the reaction of sulfuric acid with calcium-citrate [42]. However, more advanced downstream technologies, such as simulated moving bed [43], are becoming ever more established and could enable a calcium-free process, provided that it does not negatively impact the overall process efficiency. Another advantage of producing acids at low $\mathrm{pH}$ is the easier downstream processing itself, since methods such as cooling, evaporation-crystallization or salting $[20,44]$ are possible. Besides the positive effects of production at a low $\mathrm{pH}$, there are many advantages for production at near neutral $\mathrm{pH}$. One of those beneficial effects for Ustilaginaceae is the lowered burden, normally resulting from undissociated acids or low $\mathrm{pH}$ itself. Other advantages are the avoidance of thermodynamic constraints on acid export or the possibility of advanced process strategies, such as simultaneous saccharification and fermentation (SSF) in which the $\mathrm{pH}$ optimum of the applied enzymes is essential $[6,28,45]$.

$\mathrm{pH}$ values near the lower $p \mathrm{Ka}$ value of malate $\left(p \mathrm{Ka}_{1}\right.$ 3.46, $p \mathrm{Ka}_{2}$ 5.10) [15] result in undissociated malic acid. Although the molar fraction of this undissociated species is relatively low (approximately $0.002 \%$ at $\mathrm{pH}$ 6.5, $0.1 \%$ at $\mathrm{pH} 5.5$ and $4.8 \%$ at $\mathrm{pH} 4.5$; Fig. $4 \mathrm{c}$ ), its protonophoric effect likely disrupts cellular $\mathrm{pH}$ homeostasis. This, possibly coupled to an increased intracellular malic acid concentration, likely leads to the observed reduction in malate production. The weak acid uncoupling effect caused by uptake of the protonated form via diffusion with a simultaneous import of a proton and needed active transport of the dissociated form out of the cell leads to a loss of energy [45, 46]. A further loss of energy can result from the export mechanism itself. It was reported that the most likely mechanism for export of dicarboxylic acids at low $\mathrm{pH}$ is an antiport with protons [47]. This would lead to additional $\mathrm{H}^{+}$ions pumped against the proton motive force, which consequently increases ATP consumption [48]. The observation that glycerol uptake is not decreased in cultures with lower $\mathrm{pH}$, would strengthen this hypothesis, since its consumption could help to cope with the energy loss.

\section{$\mathrm{CaCO}_{3}$ as buffering agent helps to overcome product inhibition}

Independent from final $\mathrm{OD}_{600}$, malic acid production, glycerol consumption, growth rate, and temperature, a clear drop in production rate at malate concentrations above $100 \mathrm{~g} \mathrm{~L}^{-1}$ is visible and the maximal titer of around $140 \mathrm{~g} \mathrm{~L}^{-1}$ was not exceeded. In shake flask cultivations containing $\mathrm{CaCO}_{3}$ as buffer agent, however, this titer had been exceeded with constant production rates until glycerol depletion [18]. In these cultures, the $\mathrm{CaCO}_{3}$ reacts with the produced malic acid forming calcium malate, which precipitates at a concentration above $14 \mathrm{~g} \mathrm{~L}^{-1}$. As a consequence, additionally produced malate is no longer dissolved in the medium, thus alleviating product inhibition and toxicity. These results strongly suggest a negative effect of product inhibition at concentrations above $100 \mathrm{~g} \mathrm{~L}^{-1}$. 

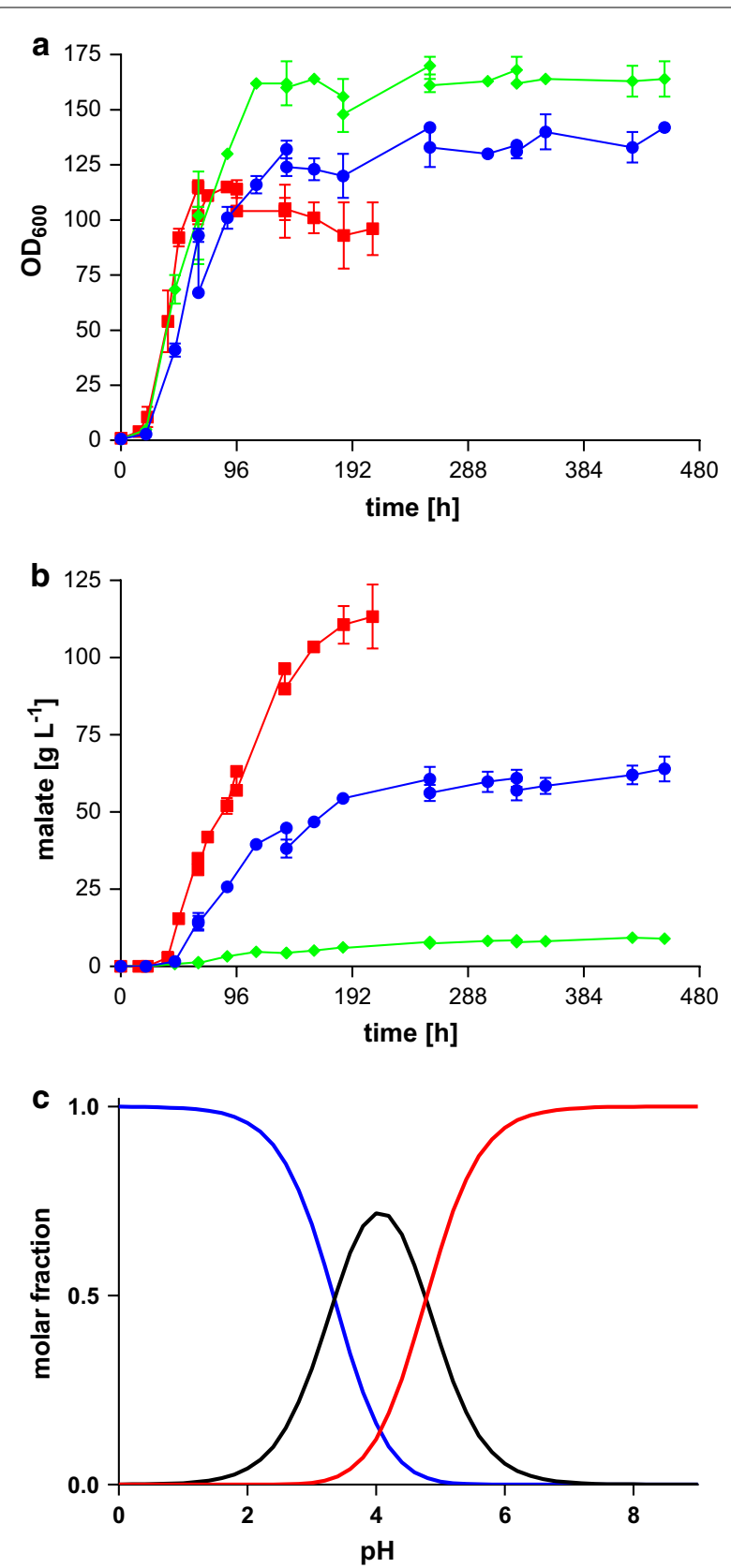

Fig. 4 Fermentation of Ustilago trichophora TZ1 at different $\mathrm{pH}$ values. a $\mathrm{OD}_{600}$, b malate concentration for fermentations in MTM containing $200 \mathrm{~g} \mathrm{~L}^{-1}$ initial glycerol and $3.2 \mathrm{~g} \mathrm{~L}^{-1} \mathrm{NH}_{4} \mathrm{Cl}$ at $30{ }^{\circ} \mathrm{C}$ and pH 6.5 with DO kept at $80 \%$. Additional $160 \mathrm{~g}$ glycerol was added when the concentration dropped below $50 \mathrm{~g} \mathrm{~L}^{-1}$. Colors indicate different $\mathrm{pH}$ values: $\mathrm{pH} 6.5$ (red), 5.5 (blue), and 4.5 (green). Error bars indicate deviation from the mean $(n=2)$. c Distribution of molar fractions of dissociated and (partly) undissociated malate species. Shown is the relative distribution of fully dissociated (blue), partially dissociated (black) and fully undissociated (red) malate dependent on the $\mathrm{pH}$ value. Data were generated using CurTiPot [56]
To overcome the assumed product inhibition in fedbatch bioreactors, cultivations with MTM containing $3.2 \mathrm{~g} \mathrm{~L}^{-1} \mathrm{NH}_{4} \mathrm{Cl}, 200 \mathrm{~g} \mathrm{~L}^{-1}$ initial glycerol and $100 \mathrm{~g} \mathrm{~L}^{-1}$ $\mathrm{CaCO}_{3}$ as buffer were performed (Fig. 5). An additional $150 \mathrm{~g} \mathrm{~L}^{-1} \mathrm{CaCO}_{3}$ was added when the $\mathrm{pH}$ dropped below 5.5 and additional $160 \mathrm{~g}$ glycerol was fed when the concentration fell below $50 \mathrm{~g} \mathrm{~L}^{-1}$. This fermentation resulted in the production of $195 \pm 15 \mathrm{~g} \mathrm{~L}^{-1}$ of malic acid within $264 \mathrm{~h}$ of cultivation, corresponding to an overall production rate of $0.74 \pm 0.06 \mathrm{~g} \mathrm{~L}^{-1} \mathrm{~h}^{-1}$. The process reached a yield of $0.43 \pm 0.05 \mathrm{~g}_{\mathrm{mal}} \mathrm{g}_{\text {gly }}^{-1}$ and a maximal production rate of $1.94 \pm 0.32 \mathrm{~g} \mathrm{~L}^{-1}$ between 47 and $71 \mathrm{~h}$ (Fig. 5a). Both glycerol consumption and malic acid production decreased over time. The yield during production phase, however, stayed constant in a range of $0.39-0.49 \mathrm{~g}_{\text {mal }} \mathrm{g}_{\text {gly }}^{-1}$, indicating that the decreasing production rate is rather

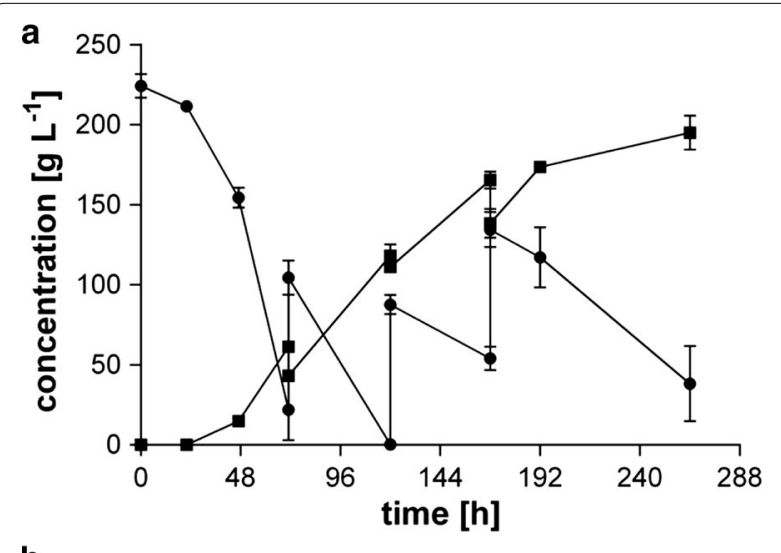

b

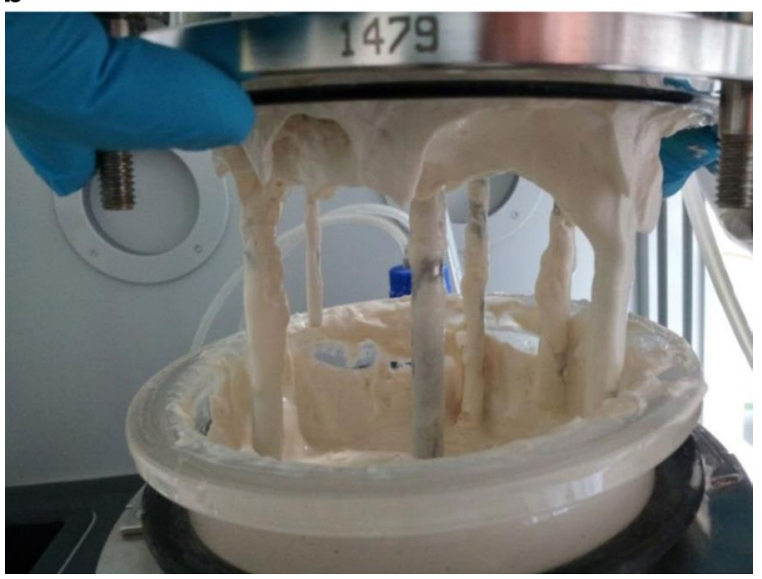

Fig. 5 Fermentation of Ustilago trichophora TZ1 with $\mathrm{CaCO}_{3}$. a malate concentration (squares) and glycerol concentration (circles), b fermentation broth after $264 \mathrm{~h}$ of fermentation in MTM containing $200 \mathrm{~g} \mathrm{~L}^{-1}$ glycerol, $3.2 \mathrm{~g} \mathrm{~L}^{-1} \mathrm{NH}_{4} \mathrm{Cl}$ and $100 \mathrm{~g} \mathrm{~L}^{-1}$ initial $\mathrm{CaCO}_{3}$ at $30^{\circ} \mathrm{C}$ with DO kept at $80 \%$ 
an effect of dilution due to glycerol feed than an actual decrease in the specific productivity.

The yield achieved with $\mathrm{CaCO}_{3}$ as buffer is 1.5 -fold higher than with $\mathrm{NaOH}$. This increase may either be due to an increase in $\mathrm{CO}_{2}$ co-fixation through the action of pyruvate carboxylase or to a reduction in product inhibition by in situ crystallization of calcium malate. Based on the current yield, and assuming that all remaining glycerol is converted to $\mathrm{CO}_{2}, 85 \%$ of the total produced $\mathrm{CO}_{2}$ originates from glycerol. The remaining $15 \%$ originates from $\mathrm{CaCO}_{3}(12 \%)$ and aeration (3\%). Given this relatively low contribution of $\mathrm{CaCO}_{3}$ to the overall $\mathrm{CO}_{2}$ balance, a positive effect of additional $\mathrm{CO}_{2}$ cometabolism from $\mathrm{CaCO}_{3}$ is unlikely. This suggests that the higher yield observed with $\mathrm{CaCO}_{3}$ is mainly due to reduction in product inhibition.

At $264 \mathrm{~h}$, the fermentation had to be stopped due to bad mixing caused by high medium viscosity (Fig. 5b) as had already been experienced for shake flask cultivations using $\mathrm{CaCO}_{3}$ as buffering agent [18]. This increased viscosity, likely caused by calcium malate, results in poor and inhomogeneous oxygenation. Further, even though the formed calcium malate can easily be recovered for downstream processing, it is linked to a large stream of gypsum waste, which results from the reaction with sulfuric acid within the downstream process as already mentioned above [42]. This gypsum needs to be disposed of as environmentally unfriendly leftover of this process. However, the prior limit of $140 \mathrm{~g} \mathrm{~L}^{-1}$ malic acid in bioreactors could be exceeded, further sustaining the hypothesis of product inhibition at concentrations above $140 \mathrm{~g} \mathrm{~L}^{-1}$. Additionally, the malic acid production rate could be kept near constant for a longer time. These advantages have to be weighed against the abovementioned drawbacks in order to determine the beneficial effect of $\mathrm{CaCO}_{3}$ as buffering agent.

As already mentioned, the formation of solid calcium malate in bioreactors containing $\mathrm{CaCO}_{3}$ as buffering agent enables efficient initial purification. To isolate the product from the fermentations, all solid components (settled for $48 \mathrm{~h}$ ) resulting from an autoclaved fermentation with $\mathrm{CaCO}_{3}$ (Fig. 5b) were dried at $120{ }^{\circ} \mathrm{C}$ for $24 \mathrm{~h}$. $0.2 \mathrm{~g}$ of this mixture was dissolved in $1 \mathrm{~mL}$ of $\mathrm{HCl}(37 \%)$ and adjusted to $2 \mathrm{~mL}$ with water in triplicates. The mixture was filtered to remove cells and the malate concentration was determined via HPLC to be $68.1 \pm 0.1 \mathrm{~g} \mathrm{~L}^{-1}$. Assuming that all products are recovered in the form of calcium malate, this is nearly $90 \%$ of the theoretical malic acid concentration $\left(78 \mathrm{~g} \mathrm{~L}^{-1}\right)$, indicating that the solids recovered from the bioreactor are $90 \%$ pure calcium malate. The remaining $10 \%$ can be assumed to be biomass and remaining $\mathrm{CaCO}_{3}$.

\section{Ustilago trichophora TZ1 can cope with impurities in crude glycerol}

Biodiesel-derived crude glycerol contains, depending on the biodiesel production process, impurities such as methanol, ash, soap, salts, non-glycerol organic matter, and water $[2,4]$. Even though different microbial conversions of crude glycerol to value-added chemicals have been reported [49], many organisms struggle with the contained impurities, especially in fed-batch cultures with high substrate loads. The purification to pharma-grade glycerol, however, is a costly process often prohibiting the possible application of glycerol in microbial chemical production. To test whether $U$. trichophora TZ1 is able to cope with the contained impurities, we investigated malic acid production with $U$. trichophora TZ1 in MTM containing 100 and $200 \mathrm{~g} \mathrm{~L}^{-1}$ crude glycerol in shake flasks. The used crude glycerol contained $1.5 \%$ ashes and $1.9 \%$ free fatty acids, with a $\mathrm{pH}$ value between 6 and 8. Neither growth rate, nor maximal optical density, nor glycerol uptake was influenced by 100 and $200 \mathrm{~g} \mathrm{~L}^{-1}$ crude glycerol compared to the same amount of pharma-grade glycerol. Malic acid production, however, was lowered by $63 \%\left(100 \mathrm{~g} \mathrm{~L}^{-1}\right)$ and $41 \%\left(200 \mathrm{~g} \mathrm{~L}^{-1}\right)$ (data not shown). This indicates that the organism itself is capable of coping with the contained impurities, although at a cost resulting in a lower malic acid titer. This in shake flasks may be due to lower oxygen input as a result of increased salt concentrations, which can be up to $12 \%$ in crude glycerol [4]. Increased osmotic pressure in media containing high concentrations of salts results in a lower maximum oxygen transfer rate in shake flasks [50]. The effect of this on growth and organic acid production was investigated in several organisms. For $U$. maydis, increased osmotic stress due to higher salt concentrations resulted in a prolonged lag-phase and lower growth rates. Interestingly, itaconic acid production slightly increased with higher salt concentrations [28], possibly due to high redox energy surplus generated with this product compared to malate. The same effect was observed in Candida oleophila with increased citric acid production with higher osmolarity of the medium [51]. Since the redox potential of the different production pathways for malic acid, succinic acid and itaconic acid is completely different, the effect of reduced oxygen transfer rates will likely differ.

To rule out this effect, we evaluated $U$. trichophora TZ1 in more industrially relevant conditions. To this end, it was cultivated in a bioreactor with MTM containing $200 \mathrm{~g} \mathrm{~L}^{-1}$ crude glycerol and $3.2 \mathrm{~g} \mathrm{~L}^{-1} \mathrm{NH}_{4} \mathrm{Cl}$. The $\mathrm{pH}$ was kept stable at 6.5 by automatic addition of $\mathrm{NaOH}$. Additional crude glycerol was fed upon glycerol depletion (Fig. 6).

This fermentation resulted in $\mathrm{OD}_{600}$ values and growth rates comparable to the ones in bioreactors 
with pharma-grade glycerol. Also the glycerol uptake rate $\left(2.90 \mathrm{~g} \mathrm{~L}^{-1} \mathrm{~h}^{-1}\right)$ and the malic acid production rate $\left(0.75 \mathrm{~g} \mathrm{~L}^{-1}\right)$ were comparable to the ones with pharmagrade glycerol. Only the yield was lowered to $0.26 \mathrm{~g} \mathrm{~g}^{-1}$. A slight negative impact of crude glycerol compared to pharma-grade glycerol on organic acid production has already been shown for Yarrowia lipolytica in citric acid production [52]. Interestingly, for $U$. trichophora TZ1 the accumulation of impurities by glycerol feed adding up to $476 \mathrm{~g}$ glycerol did not result in lowered production properties, which hints at an effect which is perhaps limited to the initial growth phase. A possibility to overcome this issue would be a second adaptive laboratory evolution on crude glycerol. For this, however, it has to be taken into consideration that depending on the origin of the crude glycerol, the composition of contained impurities differs in a broad range, not only in concentration, but also in components themselves [53]. In addition, to the already high tolerance to impurities in crude glycerol by $U$. trichophora TZ1 and thus only slight negative effect, the contained salts might also have a beneficial effect. For Actinobacillus succinogenes, it could be shown that synthetic seawater can act as mineral supplement [54].

\section{Conclusions}

The strain $U$. trichophora TZ1, which recently has been reported as promising production organism for malate from glycerol, is capable of producing $200 \mathrm{~g} \mathrm{~L}^{-1}$ malic acid at an overall rate of $0.74 \mathrm{~g} \mathrm{~L}^{-1} \mathrm{~h}^{-1}$ reaching a maximal production rate of $1.94 \mathrm{~g} \mathrm{~L}^{-1} \mathrm{~h}^{-1}$ and a yield of $0.31 \mathrm{~mol} \mathrm{~mol}^{-1}$ (31\% of the theoretical maximum assuming $\mathrm{CO}_{2}$ co-fixation or $41 \%$ assuming no $\mathrm{CO}_{2}$ co-fixation)

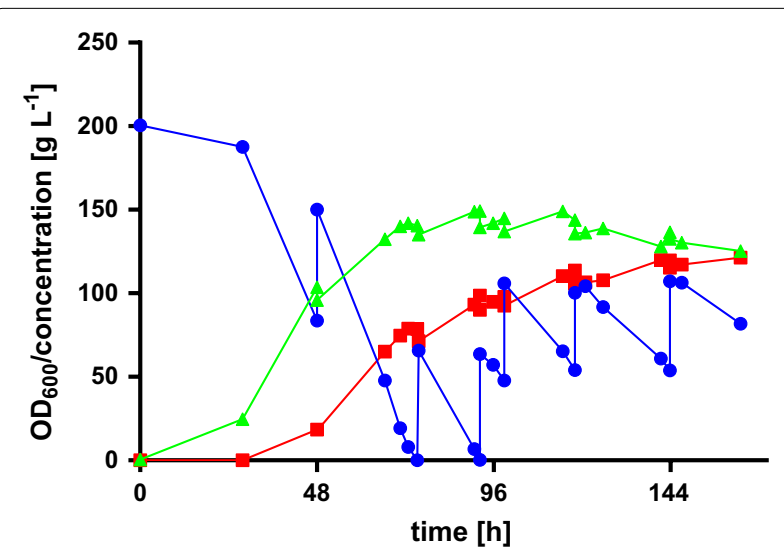

Fig. 6 Fermentation of Ustilago trichophora TZ1 with crude glycerol. Malate concentration (red, squares), glycerol concentration (blue, circles) and $\mathrm{OD}_{600}$ (green, triangles) in MTM containing $200 \mathrm{~g} \mathrm{~L}^{-1}$ crude glycerol, $3.2 \mathrm{~g} \mathrm{~L}^{-1} \mathrm{NH}_{4} \mathrm{Cl}$ at $28^{\circ} \mathrm{C}\left(37^{\circ} \mathrm{C}\right.$ during production phase, 48 h) with DO kept at $30 \%$. pH was kept at 6.5 by automatic addition of $\mathrm{NaOH}$. Shown is one exemplary fermentation run in bioreactors. These values, which are some of the highest reported for microbial malic acid production, allow $U$. trichophora TZ1, though only having undergone adaptive laboratory evolution and medium and fermentation optimization, to compete with highly engineered strains overexpressing major parts of the malate production pathway. Thus, further optimization of $U$. trichophora TZ1 could focus on metabolic engineering, which would not only harbor considerable potential to increase the production rate but also allow for strain optimization in terms of product to substrate yield by targeted disruption of by-product formation pathways. A subsequent systems biology comparison between the wild-type and the evolved strain not only could shed light on the adaptational mutations that enhanced the growth and production rate of $U$. trichophora TZ1 on glycerol but might also provide insights into why the strain utilizes glycerol faster than other Ustilaginaceae. In addition, it could clarify the glycerol uptake and degradation pathway and expand the general knowledge base of this relatively obscure Ustilago strain. This would clearly help to develop it into a platform for the production of not only malate but also other industrially relevant chemicals, to be produced from biodiesel-derived crude glycerol.

\section{Methods}

\section{Strains and culture conditions}

Ustilago trichophora TZ1 was used throughout this study [18].

As standard medium, modified Tabuchi medium (MTM) according to Geiser et al. containing $0.2 \mathrm{~g} \mathrm{~L}^{-1}$ $\mathrm{MgSO}_{4} 7 \mathrm{H}_{2} \mathrm{O}, 10 \mathrm{mg} \mathrm{L}^{-1} \mathrm{FeSO}_{4} 7 \mathrm{H}_{2} \mathrm{O}, 0.5 \mathrm{~g} \mathrm{~L}^{-1} \mathrm{KH}_{2} \mathrm{PO}_{4}$, $1 \mathrm{~mL} \mathrm{~L}^{-1}$ vitamin solution, $1 \mathrm{~mL} \mathrm{~L}^{-1}$ trace element solution [17] and differing concentrations of $\mathrm{NH}_{4} \mathrm{Cl}$ and (crude) glycerol was used. For additional glycerol feeds, $200 \mathrm{~mL}$ of an $800 \mathrm{~g} \mathrm{~L}^{-1}$ glycerol solution was added to the cultures. Additional $150 \mathrm{~g} \mathrm{CaCO}_{3}$ was fed to the cultures as solids, when the $\mathrm{pH}$ value dropped below 5.5. Pharmagrade glycerol was used for all cultures except for those where the use of crude glycerol is explicitly stated. Crude glycerol was used as $80 \%(\mathrm{w} / \mathrm{v})$ aqueous solution and autoclaved without prior purification. After addition of all medium components, the $\mathrm{pH}$ value was adjusted to 6.5.

All batch cultivations were performed in New Brunswick BioFlo ${ }^{\circledR} 110$ bioreactors (Eppendorf, Germany) with a total volume of $2.5 \mathrm{~L}$ and a working volume of $1.25 \mathrm{~L}$. Temperature was maintained at $30{ }^{\circ} \mathrm{C}$ and the $\mathrm{pH}$ value was either set to 6.5 and controlled automatically with $10 \mathrm{M} \mathrm{NaOH}$ or different amounts of $\mathrm{CaCO}_{3}$ were added as buffer. To prevent foam formation, antifoam 204 (Sigma Life Science, USA) was added automatically using level sensor control. The aeration rate was set to $1.25 \mathrm{~L} \mathrm{~min}^{-1}(1 \mathrm{vvm})$ and the dissolved oxygen 
tension (DOT) was kept at $80 \%$ saturation by automatically adjusting the stirring rate. As preculture, $50 \mathrm{~mL}$ MTM containing $0.8 \mathrm{~g} \mathrm{~L}^{-1} \mathrm{NH}_{4} \mathrm{Cl}, 50 \mathrm{~g} \mathrm{~L}^{-1}$ glycerol, and $100 \mathrm{mM}$ MES in 500-mL shake flasks was inoculated from an overnight YEP culture to an $\mathrm{OD}_{600}$ of 0.5. This culture was grown over night, washed twice by dissolving the pelleted cells $\left(5000 \mathrm{rpm}, 5 \mathrm{~min}, 30^{\circ} \mathrm{C}\right)$ in $10 \mathrm{~mL}$ distilled water and used for inoculation of the bioreactor to an initial $\mathrm{OD}_{600}$ of 0.5. All shake flask cultures were incubated at $30{ }^{\circ} \mathrm{C}$ (relative air humidity $=80 \%$ ) shaking at $200 \mathrm{rpm}$ (shaking diameter $=25 \mathrm{~mm}$ ).

\section{Analytical methods}

All experiments were performed in duplicates. Shown is the arithmetic mean of the duplicates. Error bars and \pm values indicate deviation from the mean.

From bioreactors, $5 \mathrm{~mL}$ of culture broth was taken for $\mathrm{OD}_{600}$ and HPLC analysis. When using $\mathrm{CaCO}_{3}$ as buffer, the $\mathrm{CaCO}_{3}$ in $1 \mathrm{~mL}$ culture broth was dissolved with $\mathrm{HCl}$ prior to further measurements. $\mathrm{OD}_{600}$ was determined in an Ultrospec 10 cell density meter (Amersham Biosciences, UK); samples were diluted to an $\mathrm{OD}_{600}$ between 0.1 and 0.8 .

For HPLC analysis, centrifuged samples $(13.000 g$, $5 \mathrm{~min}$ ) were filtered through cellulose acetate filters (diameter $0.2 \mu \mathrm{m}$, VWR, Germany) prior to diluting 1:10 with distilled water. For analysis of glycerol and organic acids, a Dionex Ultimate 3000 HPLC (Dionex, USA) was used with an Organic Acid Resin column (CS-Chromatographie, Germany) at $75^{\circ} \mathrm{C}$, with a constant flow rate of $0.8 \mathrm{~mL} \mathrm{~min}^{-1} 5 \mathrm{mM}$ sulfuric acid as eluent. For detection, a Shodex RI 101 detector at $35{ }^{\circ} \mathrm{C}$ and a variable wavelength UV detector (Dionex, USA) at $210 \mathrm{~nm}$ were used.

Ammonium concentration was determined by a colorimetric assay according to Willis [55].

Calculation of the molar fraction of undissociated and dissociated species for malate was performed using CurTiPot [56].

\section{Abbreviations}

MTM: Modified Tabuchi medium; MES: 2-(N-morpholino)ethanesulfonic acid; HPLC: High-performance liquid chromatography.

\section{Authors' contributions}

$L M B$, NW, and GM conceived and designed the project. TZ, NW, JMB, and LMB designed experiments and analyzed results. TZ and NW wrote the manuscript with the help of LMB and JMB. TZ, WK, and ES performed the experiments. All authors read and approved the final manuscript.

\section{Author details}

${ }^{1}$ Institute of Applied Microbiology - iAMB, Aachen Biology and Biotechnology - ABBt, RWTH Aachen University, Worringerweg 1, Aachen 52074, Germany.

2 BRAIN AG, Zwingenberg 64673, Germany.

\section{Acknowledgements}

We thank Elena Geiser for technical assistance and valuable discussion. We gratefully acknowledge BioEton for providing the (crude) glycerol.

\section{Competing interests}

GM and JMB are paid employees of BRAIN AG. The authors declare that no financial or non-financial conflict of interest was present with regard to the results or interpretation of the reported experiments. Further, they declare that this does not alter the permission of unrestricted use, distribution, and reproduction in any medium, provided the original author and source are credited.

\section{Funding}

This study was partially funded by the Biotechnology Research And Information Network AG (BRAIN AG) and by the German Federal Ministry of Education and Research (BMBF) as part of the Strategic Alliance ZeroCarbFP (Grant No. FKZ 031A217F)

Received: 24 March 2016 Accepted: 23 June 2016

Published online: 02 July 2016

\section{References}

1. Anand P, Saxena RK. A comparative study of solvent-assisted pretreatment of biodiesel derived crude glycerol on growth and 1,3-propanediol production from Citrobacter freundii. New Biotechnol. 2012;29(2):199-205.

2. Yang F, Hanna MA, Sun R. Value-added uses for crude glycerol-a byproduct of biodiesel production. Biotechnol Biofuels. 2012;5:13.

3. West TP. Crude glycerol: a feedstock for organic acid production by microbial bioconversion. J Microbial Biochem Technol. 2012;4:ii-ii. doi:10.4172/1948-5948.1000e106.

4. Nicol RW, Marchand K, Lubitz WD. Bioconversion of crude glycerol by fungi. Appl Microbiol Biotechnol. 2012;93(5):1865-75.

5. Goldberg I, Rokem JS, Pines O. Organic acids: old metabolites, new themes. J Chem Technol Biotechnol. 2006;81(10):1601-11.

6. Sauer M, Porro D, Mattanovich D, Branduardi P. Microbial production of organic acids: expanding the markets. Trends Biotechnol. 2008;26(2):100-8.

7. Werpy T, Petersen GR, Aden A, Bozell JJ, Holladay J, White J, Manheim A, Eliot D, Lasure $L$, Jones S. Top value added chemicals from biomass. Volume 1-Results of screening for potential candidates from sugars and synthesis gas; 2004; US-DoE Report PNNL-16983.

8. Battat E, Peleg Y, Bercovitz A, Rokem JS, Goldberg I. Optimization of L-malic acid production by Aspergillus flavus in a stirred fermentor. Biotechnol Bioeng. 1991;37(11):1108-16.

9. Knuf C, Nookaew I, Remmers I, Khoomrung S, Brown S, Berry A, Nielsen J. Physiological characterization of the high malic acid-producing Aspergillus oryzae strain 2103a-68. Appl Microbiol Biotechnol. 2014;98(8):3517-27.

10. Peleg Y, Stieglitz B, Goldberg I. Malic acid accumulation by Aspergillus flavus. Appl Environ Microbiol. 1988;28:69-75.

11. Abe S, Furuya A. Method of producing L-malic acid by fermentation. 1962; Patent US3063910.

12. Magnuson JK, Lasure LL. Organic acid production by filamentous fungi. In:Tkacz JS, Lange L, editors. Advances in fungal biotechnology for industry, agriculture and medicine. Springer: New York; 2004. p. 307-40.

13. Moon SY, Hong SH, Kim TY, Lee SY. Metabolic engineering of Escherichia coli for the production of malic acid. Biochem Eng J. 2008;40(2):312-20.

14. Zhang $X$, Wang $X$, Shanmugam KT, Ingram LO. L-malate production by metabolically engineered Escherichia coli. Appl Environ Microbiol. 2011;77(2):427-34.

15. Zelle RM, de Hulster E, van Winden WA, de Waard P, Dijkema C, Winkler AA, Geertman JM, van Dijken JP, Pronk JT, van Maris AJ. Malic acid production by Saccharomyces cerevisiae: engineering of pyruvate carboxylation, oxaloacetate reduction, and malate export. Appl Environ Microbiol. 2008;74(9):2766-77.

16. Brown SH, Bashkirova L, Berka R, Chandler T, Doty T, McCall K, McCulloch M, McFarland S, Thompson S, Yaver D, et al. Metabolic engineering of Aspergillus oryzae NRRL 3488 for increased production of L-malic acid. Appl Microbiol Biotechnol. 2013;97(20):8903-12.

17. Geiser E, Wiebach V, Wierckx N, Blank LM. Prospecting the biodiversity of the fungal family Ustilaginaceae for the production of value-added chemicals. BMC Fungal Biol Biotechnol. 2014;1:2. 
18. Zambanini T, Sarikaya E, Kleineberg W, Buescher JM, Meurer G, Wierckx N, Blank LM. Efficient malic acid production from glycerol with Ustilago trichophora TZ1. Biotechnol Biofuels. 2016;9(1):1-8.

19. Maassen N, Panakova M, Wierckx N, Geiser E, Zimmermann M, Bölker M, Klinner U, Blank LM. Influence of carbon and nitrogen concentration on itaconic acid production by the smut fungus Ustilago maydis. Eng Life Sci. 2013;14(2):129-34.

20. Klement T, Büchs J. Itaconic acid - a biotechnological process in change. Bioresour Technol. 2013;135:422-31.

21. Feldbrügge M, Kellner R, Schipper K. The biotechnological use and potential of plant pathogenic smut fungi. Appl Microbiol Biotechnol. 2013;97(8):3253-65.

22. Bölker M, Basse CW, Schirawski J. Ustilago maydis secondary metabolism—from genomics to biochemistry. Fungal Genet Biol. 2008:45:88-93.

23. Guevarra ED, Tabuchi T. Accumulation of itaconic, 2-hydroxyparaconic, itatartaric, and malic acids by strains of the genus Ustilago. Agr Biol Chem Tokyo. 1990;54(9):2353-8.

24. Jeya M, Lee KM, Tiwari MK, Kim JS, Gunasekaran P, Kim SY, Kim IW, Lee JK. Isolation of a novel high erythritol-producing Pseudozyma tsukubaensis and scale-up of erythritol fermentation to industrial level. Appl Microbiol Biotechnol. 2009;83(2):225-31.

25. Moon HJ, Jeya M, Kim IW, Lee JK. Biotechnological production of erythritol and its applications. Appl Microbiol Biotechnol. 2010;86(4):1017-25.

26. Giese H, Azizan A, Kummel A, Liao A, Peter CP, Fonseca JA, Hermann R, Duarte TM, Buchs J. Liquid films on shake flask walls explain increasing maximum oxygen transfer capacities with elevating viscosity. Biotechnol Bioeng. 2014;111(2):295-308.

27. Gyamerah $\mathrm{MH}$. Oxygen requirement and energy relations of itaconic acid fermentation by Aspergillus terreus NRRL 1960. Appl Microbiol Biotechnol. 1995;44(1-2):20-6.

28. Klement T, Milker S, Jäger G, Grande PM, de Maria PD, Büchs J. Biomass pretreatment affects Ustilago maydis in producing itaconic acid. Microb Cell Fact. 2012;11:43.

29. Morita T, Fukuoka T, Imura T, Kitamoto D. Production of glycolipid biosurfactants by basidiomycetous yeasts. Biotechnol Appl Biochem. 2009;53:39-49.

30. Hewald S, Linne U, Scherer M, Marahiel MA, Kämper J, Bölker M. Identification of a gene cluster for biosynthesis of mannosylerythritol lipids in the basidiomycetous fungus Ustilago maydis. Appl Environ Microbiol. 2006;72(8):5469-77.

31. Teichmann B, Linne U, Hewald S, Marahiel MA, Bolker M. A biosynthetic gene cluster for a secreted cellobiose lipid with antifungal activity from Ustilago maydis. Mol Microbiol. 2007:66(2):525-33.

32. Geiser E. Itaconic acid production by Ustilago maydis, vol. 1. Aachen: Apprimus; 2015.

33. Duskova M, Borovikova D, Herynkova P, Rapoport A, Sychrova H. The role of glycerol transporters in yeast cells in various physiological and stress conditions. FEMS Microbiol Lett. 2015;362(3):1-8.

34. Duskova M, Ferreira C, Lucas C, Sychrova H. Two glycerol uptake systems contribute to the high osmotolerance of Zygosaccharomyces rouxii. Mol Microbiol. 2015;97(3):541-59.

35. Guevarra ED, Tabuchi T. Production of 2-hydroxyparaconic and itatartaric acids by Ustilago cynodontis and simple recovery process of the acids. Agric Biol Chem Tokyo. 1990;54(9):2359-65.

36. Kuenz A. Itaconsäureherstellung aus nachwachsenden Rohstoffen als Ersatz für petrochemisch hergestellte Acrylsäure. Dissertation. Braunschweig: Technischen Universität Carolo-Wilhelmina Braunschweig, Germany; 2008.

37. Park Y, Ohta N, Okabe M. Effect of dissolved oxygen concentration and impeller tip speed on itaconic acid production by Aspergillus terreus. Biotechnol Lett. 1993;15(6):583-6.
38. Yahiro K, Takahama T, Park YS, Okabe M. Breeding of Aspergillus terreus mutant TN-484 for itaconic acid production with high yield. J Ferment Bioeng. 1995;79(5):506-8.

39. Hevekerl A, Kuenz A, Vorlop K-D. Filamentous fungi in microtiter platesan easy way to optimize itaconic acid production with Aspergillus terreus. Appl Microbiol Biotechnol. 2014:98(16):6983-9.

40. Yuzbashev TV, Yuzbasheva EY, Sobolevskaya TI, Laptev IA, Vybornaya TV, Larina AS, Matsui K, Fukui K, Sineoky SP. Production of succinic acid at low $\mathrm{pH}$ by a recombinant strain of the aerobic yeast Yarrowia lipolytica. Biotechnol Bioeng. 2010;107(4):673-82.

41. Yuzbashev TV, Yuzbasheva EY, Laptev IA, Sobolevskaya TI, Vybornaya TV, Larina AS, Gvilava IT, Antonova SV, Sineoky SP. Is it possible to produce succinic acid at a low pH? Bioeng Bugs. 2011;2(2):115-9.

42. Amy HAM, Berovic M, Gluszca P, Kristiansen B, Krzystek L, Kubicek C, Ledakowicz S, Lesniak W, Mattey M, Papagianni M et al. Citric acid biotechnology. In. Kristiansen B, Mattey M, Linden J, editors. Taylor \& Francis e-Library; 2002

43. Wu J, Peng Q, Arlt W, Minceva M. Model-based design of a pilot-scale simulated moving bed for purification of citric acid from fermentation broth. J Chromatogr A. 2009;1216(50):8793-805.

44. Adams Jr. F, Rice LF, Taylor RJ. Itaconic acid purification process using reverse osmosis. 1970; Patent US3544455.

45. van Maris AJ, Konings WN, van Dijken JP, Pronk JT. Microbial export of lactic and 3-hydroxypropanoic acid: implications for industrial fermentation processes. Metab Eng. 2004;6(4):245-55.

46. Abbott DA, Zelle RM, Pronk JT, van Maris AJ. Metabolic engineering of Saccharomyces cerevisiae for production of carboxylic acids: current status and challenges. FEMS Yeast Res. 2009;9(8):1123-36

47. Jamalzadeh E, Verheijen PJ, Heijnen JJ, van Gulik WM. pH-dependent uptake of fumaric acid in Saccharomyces cerevisiae under anaerobic conditions. Appl Environ Microbiol. 2012;78(3):705-16.

48. Jamalzadeh E, Taymaz-Nikerel H, Heijnen JJ, van Gulik WM, Verheijen PJT. A thermodynamic analysis of dicarboxylic acid production in microorganisms. In: von Stockar U, van der Wielen LAM, Prausnitz JM, editors. Thermodynamics in biochemical engineering. Switzerland: Lausanne; 2012.

49. Dobson R, Gray V, Rumbold K. Microbial utilization of crude glycerol for the production of value-added products. J Ind Microbiol Biotechnol. 2012;39(2):217-26.

50. Morgan MJ, Lehmann M, Schwarzländer M, Baxter CJ, Sienkiewicz-Porzucek A, Williams TC, Schauer N, Fernie AR, Fricker MD, Ratcliffe RG, et al. Decrease in manganese superoxide dismutase leads to reduced root growth and affects tricarboxylic acid cycle flux and mitochondrial redox homeostasis. Plant Physiol. 2008;147(1):101-14.

51. Anastassiadis S, Aivasidis A, Wandrey C. Citric acid production by Candida strains under intracellular nitrogen limitation. Appl Microbiol Biotechnol. 2002;60(1-2):81-7.

52. Rymowicz W, Rywinska A, Marcinkiewicz M. High-yield production of erythritol from raw glycerol in fed-batch cultures of Yarrowia lipolytica. Biotechnol Lett. 2009;31(3):377-80.

53. Samul D, Leja K, Grajek W. Impurities of crude glycerol and their effect on metabolite production. Ann Microbiol. 2014;64:891-8.

54. Lin CSK, Luque R, Clark JH, Webb C, Du C. A seawater-based biorefining strategy for fermentative production and chemical transformations of succinic acid. R Soc Chem Adv. 2011:4(4):1471-9.

55. Willis RB, Montgomery ME, Allen PR. Improved method for manual, colorimetry determination of total Kjeldahl nitrogen using salicylate. J Agric Food Chem. 1996;44(7):1804-7.

56. CurTiPot. $\mathrm{pH}$ and acid-base titration curves: analysis and simulation freeware, version 4.2. http://www.iq.usp.br/gutz/Curtipot_.html. 23 May 2016. 